\title{
TWO NEW SPECIES OF THE ANT GENUS PERISSOMYRMEX SMITH (HYMENOPTERA: FORMICIDAE) FROM CHINA ${ }^{1}$
}

\author{
Shanyi Zhou ${ }^{2}$ and Jianhua Huang ${ }^{3}$
}

\begin{abstract}
Two new species of the ant genus Perissomyrmex Smith are described in the paper, i.e. P. guizhouensis sp. nov., P. bidentatus sp. nov. A key based on minor worker caste to all known species in the world is provided.
\end{abstract}

KEY WORDS: Hymenoptera; Formicidae; Perissomyrmex; new species, China

The ant genus Perissomyrmex was described by M. R. Smith in 1947 based on the type species $P$. snyderi Smith (Smith M. R., 1947). The genus originally contained a single species described from two minor workers collected at the Hoboken plant quarantine station of New Jersey, U.SA. The specimens were found in the tuberous root of a Begonia plant shipped from Guatemala, but there is no evidence that Guatemala, or Mesoamerica, is the center of origin for this species. Bolton (1981) suspected that the species were brought to the USA via Guatemala through human commerce from somewhere in the Oriental or the IndoAustralian region. De Andrade (in Baroni Urbani and de Andrade, 1993) described the second species of the genus, P. monticola, based on two minor workers and a dealated queen from Bhutan. In their paper, Baroni Urbani and de Andrade supported Bolton's opinion and suggested that the genus Perissomyrmex has Old World origins and proposed that $P$. snyderi had been introduced into Guatemala. However, in the following year, P. snyderi was found in Mexico (Longino and Hartley, 1994) and the queen was first described. Longino and Hartley showed in their paper that $P$. snyderi is a polymorphic species and postulated that Perissomyrmex has a disjunct distribution. They also predicted that additional populations (or species) of this genus would be found in isolated and specialized habitats. Two more Old World species of Perissomyrmex have been described recently, P. nepalensis, from Nepal and India (Radchenko, 2003) and P. fissus, from China (Xu and Wang, 2004). The description of these two species, as well as two new species (this paper), supports the disjunct distribution and the Old World origin hypotheses for Perissomyrmex.

\footnotetext{
${ }^{1}$ Received on June 14, 2005. Accepted on November 4, 2005

${ }^{2}$ College of Life Science, Guangxi Normal University, Guilin, Guangxi 541004 P. R.China. E-mail: syzhou@mailbox.gxnu.edu.cn, caniscn@mailbox.gxnu.edu.cn, respectively.
} 


\section{METHODS}

The measurements, in $\mathrm{mm}$, and indices used in this paper are as defined in Bolton (1981).

Total length (TL) = total outstretched length of the individual, from mandibular apex to gastral apex.

Head Length $(\mathrm{HL})=$ length of the head proper, excluding the mandibles, measured from the anterior clypeal border including its teeth to the midpoint of the occipital margin, in a straight line in full-face view.

Head Width $(\mathrm{HW})=$ maximum width of the head in front of the eyes, measured in full-face view.

Cephalic Index (CI) = HWx100/HL.

Scape Length $(\mathrm{SL})=$ straight-line length of the antennal scape, excluding the basal constriction or neck close to the articulating condylar bulb.

Scape Index $(\mathrm{SI})=\mathrm{SLx} 100 / \mathrm{HW}$

Pronotal Width $(\mathrm{PW})=$ maximum width of the pronotum in dorsal view.

Alitrunk Length $(\mathrm{AL})=$ diagonal length of the alitrunk in lateral view from the point at which the pronotum meets the cervical shield to the posterior base of the metapleural lobes.

Eye length $(\mathrm{EL})=$ maximum length of the eye.

Petiole length (PL) = length of the petiole, from the lateral flanges of the anterior peduncle to the posterior margin of the petiole in lateral view.

Petiole Height $(\mathrm{PH})=$ maximum height of the petiole in lateral view measured from the ventral to the highest of the petiole in a straight line excluding any subprocess.

Petiolar Node Width $(\mathrm{PNW})=$ maximum width of the petiolar node in dorsal view.

Postpetiole Length $(\mathrm{PPL})=$ maximum length of the postpetiole, from the anterior margin to the posterior margin of the postpetiole.

Petiole Index $(\mathrm{PI})=\mathrm{PNWx} 100 / \mathrm{PL}$ posterior margin of the postpetiole in lateral view. 
Postpetiole Height $(\mathrm{PPH})=$ maximum height of the postpetiole in lateral view measured from the ventral to the highest in a straight line excluding any subpetiolar process.

Postpetiole Width $(\mathrm{PPW})=$ maximum width of the postpetiole in dorsal view.

Postpetiole Index $(\mathrm{PPI})=$ PPWx100/PPL.

\section{SYSTEMATIC ENTOMOLOGY}

\section{Perissomyrmex guizhouensis sp. nov.}

Figs. 1-3

Holotype, minor worker. TL 3.9, HL 0.98, HW 0.98, SL 0.86, EL 0.10, AL 1.05, PW 0.56, PL 0.34, PNW 0.17, PH 0.27, PPL 0.27, PPW 0.23, PPH 0.29, CI 100 , SI 87 , PI 50, PPI 85. Head as broad as long, widened forward. In full face view, occipital margin weakly convex, occipital corners rounded, sides slightly convex. Mandible rectangular, inner margin with one tooth in the middle, masticatory margin with 3 teeth and a diastema, arranged as apical tooth, preapical tooth, diastema and basal tooth. Median region of clypeus flattened, anterior clypeal border with 4 teeth: the central pair slightly larger than the two external teeth. Frontal carinae absent leaving antennal sockets completely exposed. Antenna 9-segmented, apical three enlarged to form antennal club. Antennal scape surpassing occipital corner by $1 / 6$ of its length. Eyes protuberant but small, placed at the middle length of the sides of the head. In profile view, pronotum slightly convex, promesonotal suture absent. Propodeal impression well developed. Propodeal spines divergent, directed backwards, dorsum of propodeum slightly convex. Petiole 2 times longer than broad, without subpetiolar process. Petiolar node relatively high and thin, weakly narrowed upwards, dorsum moderately convex, anterodorsal corner higher than posterodorsal corner. Anteroventral corner of postpetiole right-angled, postpetiolar node inclined posteriorly, as high as petiolar node.

Mandible coarsely longitudinally striate. Clypeus smooth and shining. Head and alitrunk sparsely longitudinally striate. Lateral sides of mesothorax, metathorax smooth and shining, propodeum sparsely longitudinally striate. Petiole and postpetiole sparsely longitudinally striate. Gaster smooth and shining. Dorsal surfaces of head and body with abundant erect or suberect long hairs and subdecumbent short hairs. Antennal scapes and tibiae with abundant subdecumbent long hairs and decumbent short hairs. Color reddish brown, antennal scapes and legs lighter, gaster darker.

Major worker: TL 3.9, HL 1.00, HW 1.00, SL 0.78, EL 0.12, AL 1.06, PW 0.56, PL 0.34, PNW 0.17, PH 0.27, PPL 0.27, PPW 0.23, PPH 0.29, CI 100, SI 
78, PI 50, PPI 85 (two specimens measured, the measurements are the same). Head slightly larger than that of minor, with distinct ocelli, eyes larger than that of minor, occipital margin distinctly broadly concave, antennal scapes shorter than that of minor, anterior clypeal border without notch, its center prominent and lateral with two indistinct blunt teeth. Other characters are as those of minor. Paratype workers: TL 3.9-4.0, HL 0.95-100, HW 0.95-100, SL 0.78-0.86, EL 0.10-0.12, AL 1.03-1.06, PW 0.54-0.56, PL 0.32-0.34, PNW 0.16-0.17, PH 0.26-0.27, PPL 0.27-0.29, PPW 0.22-0.23, PPH 0.27-0.29, CI 98-100, SI 78-87, PI 50-54, PPI 81-85 (2 major and 4 minor measured).

Holotype minor worker, Fanjing Mountain Natural Reserve (1980 m), Guizhou Province, $27^{\circ} 49^{\prime} \mathrm{N}, 108^{\circ} 45^{\prime} \mathrm{W}, 31$ May 2002, Shanyi Zhou leg. Paratype 2 major workers, 3 minor workers, data as holotype. All the types were collected in primeval forest floor leaf litter sample.

This new species differs from $P$. fissus Xu by anterolateral clypeal border each with 1 tooth beside the central teeth, antennal scape shorter, SI $=85$ (the latter $=$ 91), mandibles coarsely longitudinally striate. It differs from P. snyderi M. Smith by central notch of anterior clypeal border deep and U-shaped, sculptures on pronotum longitudinal, color reddish brown. It differs from $P$. monticola de Andrade by the central pair teeth of the anterior clypeal border slightly larger than the two external teeth, petiole 2 times longer than broad, pronotum longitudinally striate.

\section{Perissomyrmex bidentatus sp. nov.}

Figs. 4-6

Holotype minor worker. TL 3.8, HL 0.93, HW 0.93, SL 0.73, EL 0.10, AL 1.03, PW 0.56, PL 0.31, PNW 0.17, PH 0.28, PPL 0.24, PPW 0.22, PPH 0.28, CI 100, SI 78, PI 54, PPI 91. Head as broad as long, widened forward. In full face view, occipital margin slightly concave, occipital corners rounded, sides slightly convex. Mandible rectangular, inner margin with one tooth in the middle, masticatory margin with 3 teeth and a diastema, arranged as apical tooth, preapical tooth, diastema and basal tooth. Median region of clypeus flattened, anterior clypeal border with 4 teeth: the central pair slightly larger than the two external teeth. Frontal carinae absent leaving antennal sockets completely exposed. Antenna 9-segmented, apical three enlarged to formed antennal club. Antennal scape surpassing occipital corner by $1 / 6$ of its length. Eyes protuberant but small, placed at the middle length of the sides of the head. In profile view, pronotum slightly convex, promesonotal suture poorly distinguishable. Propodeal impression well developed. Propodeal spines divergent, directed backwards, dorsum of propodeum slightly convex. Petiole 2 times longer than broad, without subpetiolar process. Petiolar node relatively high and thin, weakly narrowed upwards, dorsum moderately convex, anterodorsal corner higher than posterodorsal corner. Anteroventral corner of postpetiole right-angled, postpetiolar node inclined posteriorly, as high as petiolar node. 
Mandible coarsely longitudinally striate. Clypeus smooth and shining. Head and alitrunk sparsely longitudinally striate. Lateral sides of mesothorax, metathorax smooth and shining, propodeum sparsely longitudinally striate, and the striations on pronotum concentrate on humeri. Petiole and postpetiole smooth and shining. Gaster smooth and shining. Dorsal surfaces of head and body with abundant erect or suberect long hairs hairs. Antennal scapes and tibiae with abundant subdecumbent long hairs and decumbent short hairs. Color reddish brown, antennal scapes and legs lighter, gaster darker.

Paratype minor worker: TL 3.9, HL 0.93, HW 0.93, CI 100, SL 0.73, SI 78, EL 0.10, AL 1.03, PW 0.56, PL 0.31, PNW 0.17, PH 0.27, PI 54, PPL 0.24, PPW 0.22, PPH 0.29, PPI 91.

Holotype worker, Baiyun Mountain, Song County, Henan Province, 33³8'N, $111^{\circ} 48^{\prime}$ W. 25 July 2002, Jianhua Huang leg. Paratype 1 worker, Qinling Natural Reserve, Shaanxi Province, $32^{\circ} 40^{\prime}$ N, $105^{\circ} 30^{\prime} W, 9$ July 2004, Ru Tie leg.

This new species differs from all known species by anterior clypeal border with 2 teeth. It differs from $P$. guizhouensis sp. nov. by occipital border slightly concave, central clypeal lobes without external teeth, antennal scape shorter, SI 78 , promesonotal suture poorly distinguishable.

The holotype is deposited in the Insect Collection, Guangxi Normal University, Guilin, P. R. China. The paratypes of P. guizhouensis sp. nov. will be deposited in Natural History Museum of Los Angeles Country, California (U.S.A.), CSIRO Division of Entomology, Canberra (Australia), and in the Faculty of Science, Kagoshima University (Kagoshima, Japan).

\section{A key to the known species of the genus Perissomyemex Smith of the World based on minor worker caste}

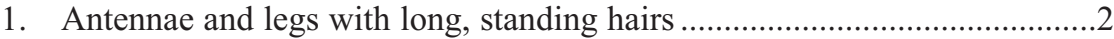

- Antennae and legs with much shorter standing hairs ................................

2. (1) Central pair of clypeal lobes short. Sculpture on head dorsum denser, frons between frontal carinae level with the eyes, having not less than 14 costulae. Appendages dark brown (Central America)

P. snyderi Smith, 1947

- Central pair of clypeal lobes long. Sculpture on head dorsum sparser, frons between frontal carinae level with the eyes, having 10-11 costulae. Appendages brownish-yellow (Nepal, India) 


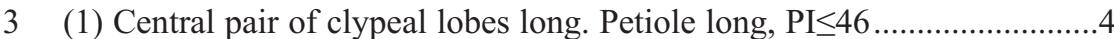

- Central pair of clypeal lobes short. Petiole short, PI $\geq 50 \ldots \ldots \ldots \ldots \ldots \ldots \ldots \ldots \ldots . . . .5$

4 (3) Petiole long, 3 times longer than broad, PI 36. Pronotum transversely striate (Bhutan) P. monticola de Andrade, 1993

- Petiole shorter, 2 to 2.5 times longer than broad, PI 46. Pronotum longitudinally striate (China) P. fissus Xu et Wang, 2004

5 (3) Central clypeal lobes each with one external tooth which is close to, and slightly shorter than the central lobes. Antennal scape longer, SI 87. Pronotum longitudinally striate (China) P. guizhouensis sp. nov.

- Central clypeal lobes without external teeth. Antennal scape shorter, SI 78. Pronotum concentrically striate on humeri (China).

P. bitentatus sp. nov.

Remarks: All of the four known species were described based on minor worker caste, Longino and Hartley (1994) reported that the genus is polymorphic. Fortunately, we collected two major workers of $P$. guizhouensis sp. nov. during the course of an entomological investigation on the Fanjing Mountain Nature Reserve, Guizhou Province of China. The major workers are not larger than the minor worker, but the head has distinct ocelli and very different shape. This find provides strong evidence for Longino and Hartley's record.

\section{ACKNOWLEDGEMENTS}

This study is supported by the National Natural Science Foundation of China (Project No. 30360013) and Science Foundation of Guangxi (Project No. GKJ0236015). We thank Prof. John T. Longino (The Evergreen State College, USA), Dr. Donat Agosti (Department of Entomology, American Museum of Natural History, USA), Prof. Alexander Radchenko (Museum and Institute of Zoology, Poland) and Dr. Zhenghui Xu (The College Library, Southwest Forestry College, China) for sending us papers, Dr. Brian Fisher and Dr. April Nobile (Associate Curator and Chair Entomology, California Academy of Sciences) for preparing images, Professor Zizhong Li (Institute of Insects, Guizhou University, China) and Prof. Xiaocheng Shen (Institute of Plant Protection, Henan Academy of Agricultural Sciences, China) for giving us opportunities to join the programs of investigating on insects of Fan Jing Mountain Natural Reserve and Baiyun Mountain Natural Reserve. 

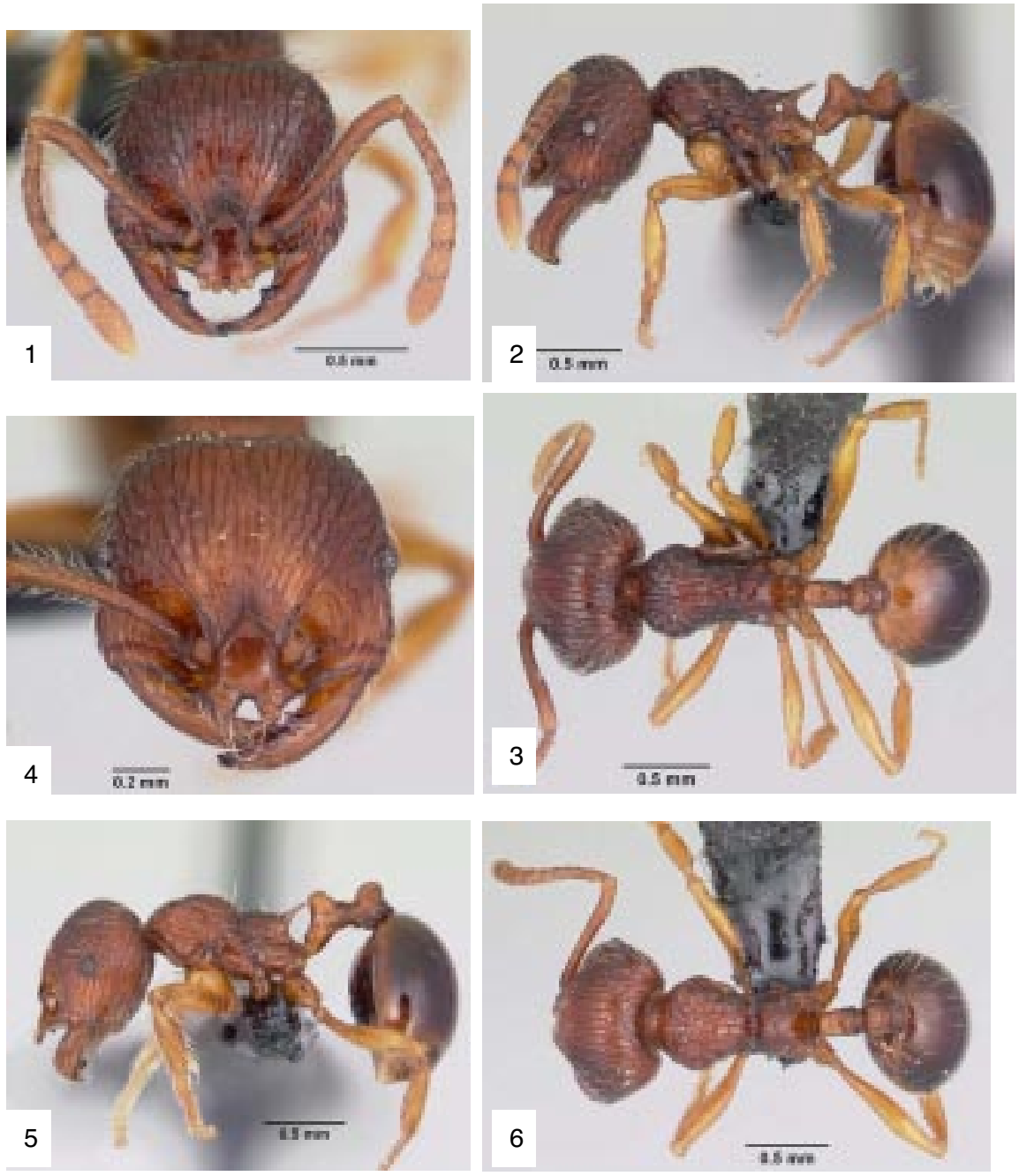

Figures 1-6. Perissomyrmex minor workers. 1-3. P. guizhouensis sp. nov. 4-6. P. bidentatus sp. nov. 1, 4. head in full face view 2, 5. body in profile 3,6. alitrunk in dorsal view. 


\section{LITERATURE CITED}

Bolton, B. 1981. A revision of six minor genera of Myrmicinae (Hymenoptera: Formicidea) in the Ethiopian Zoogeographical region. Bulletin of the British Museum (Natural History) Entomology 43 (1): 245-307.

Baroni Urbani, C. and M. L. de Andrade 1993. Perissomyrmex monticola n. sp. from Bhutan: the first natural record for a presumed Neotropical genus with a discussion on its taxonomic study. Tropical Zoology 6 (1): 89-95.

Longino, J. T. and D. A. Hartley. 1994. Perissomyrmex snyderi (Hymenoptera: Formicidae) is native to Central America and exhibits worker polymorphism. Psyche (Cambrige) 101(3-4): $195-202$

Radchenko, A. 2003. Perissomyrmex nepalensis sp. n. (Hymenoptera, Formicidae) a new evidence of Old World origin of the genus. Entomologica Basiliensia 25: 13-22.

Smith, M. R. 1947. A new genus and species of ant from Guatemala (Hymenoptera: Formicidae). Journal of the New York Entomological Society. 55 (4): 281-284.

Xu, Z. and W. Wang. 2004. The Third Species of the Ant Genus Perissomyrmex Smith (Hymenoptera: Formicidae) in the World. Entomotaxonomia 26 (3): 217-221. 